\title{
Paloma Leyton
}

Université du Québec à Montréal

\section{Gravity Matters:}

Circus as a Device.

An Approach on Staging

the Relationship between

\section{Human Beings and Gravity}

Times of crisis are also a chance for reformulation. While the Covid-19 pandemic is still relentlessly hitting the professional scene of the arts, we art workers have had to start exploring resilience tactics that, in many cases, have led us to rely on our institutions for solutions. As a result of one of these strategies, a month ago I found myself sitting in the meeting room of the third floor of the Spanish Ministry of Culture. There, at the headquarters of the National Institute for Scenic Arts and Music (INAEM), I was selected for an education grant in cultural management.

As I was sitting there alone, for a moment, I was drawn to the glass walls that separate the rooms of INAEM. These walls are decorated with the written words teatro, danza, lírica, música, circo (Spanish for theatre, dance, lyrical theatre, music and circus), which are the disciplines for which the institution provides funding, circuits and prizes. I imagined that if I had been in the same room thirty years earlier, the word 'circus' would be missing from the list. In fact, the Ministry of Culture's first regulations for Circus grants and a national prize appeared in 1990, while the first general development plan for Circus at a national level was not put into practice until 2011. This case is just the Spanish example of the late inclusion of circus arts in national institutions of culture, which partially explains why it is often seen as an underrated branch of the arts in academia. 
Despite our current and past crises, circus arts have gone a long way in fighting for recognition as historical and cultural patrimony, resulting in a global growth of active agents and schools, besides artistic proliferation, research and development. Nevertheless, the economic structures of cultural institutions, as well as most education systems, tend to follow disciplinary criteria. To provide a concrete example, circus companies that want to enter institutional circuits must adapt to a criterion (that determines what 'is' and what 'is not' Circus) which sees Circus as an art form but does not do justice to Circus' creative potential as a complex device. I believe, after my humble experience as an artist and as a researcher, that approaching creative processes from a disciplinary mindset conditions the resulting work enormously. Such an approach narrows the possibilities of the process itself into a discipline-based format that yet satisfies the rules of institutional circuits. In other words, the substance is conditioned by the form. The point of view that inspires this article is influenced by a complex perspective, based on the study of macro-subjects through different branches of knowledge in order to better comprehend its global, complex nature (Morin, 1990). Therefore, it is substance-based.

This article aims at understanding Circus as a creative device in order to provide an alternative approach to the study of contemporary circus creation. To this effect, it will be organised into three main parts. Stating and justifying Circus as a device and studying its main subject, integrating nouveau cirque and contemporary Circus within the history of art from post-modern currents to our days, and displaying practical examples of these first two points by studying selected work from a series of artists that are active today.

\section{Circus as a device}

According to Giorgio Agamben (2006), a device can be literally anything that can capture, orientate, determine, intercept, model, control and assure gestures, behaviours, opinions and speeches of living beings. Not only agents and things that exert power in an evident or legal way, but also everything that has to do with language, communication and disciplinary tradition can be devices. Following this logic, art procedures and artworks can be devices as well, simply because art is both aesthetic experience and embodied theory. The most immediate proof of this is the generalised existence of art education in museums and institutions alike, a mediation work that can be done literally with any kind of art product or process and for any kind of audience. The most extreme example, on the other hand, might be the use of art by different political forces through the course of history as a vehicle for propaganda and mass manipulation. Circus, 
which is as old as human civilisations, is a device whose complexity comes from its very nature.

The word circus (Latin for circle), which was brought back by Philip Astley to name his equestrian shows in a circular stage, today circles around a vast, plural range of people, disciplines, art, education objects, theory, spaces, creative processes, and general showbiz. Ranging from purely physical skill to different dimensions of performance arts, or from millenary traditions to the latest advances in technology, this big circle can also become a roundabout that intersects historical, performative, scientific and humanistic studies. After the removal of animal acts (of mere exhibitionist nature) from the ring and the abandonment of the idea of a mass entertainment-oriented circus that focuses only on a display of physical feats, the position of circus today is at a crossroad between its ancient traditions and the most diverse artistic innovations. The dexterity of the performers' body does not only look for the viewer's wonder but seeks to be consciously filled with meaning. This way, the audience is confronted with a series of bodies that invoke, through their presence and movement and through the sense that they embody, a battle against risk and danger that is rarely lost.

Another meaning of the Latin word circus is "orbit", which is an interesting coincidence. Plural and diverse as they may be, the common thread behind most circus acts is found in their staging - at their most essential level - of the relationship between human beings and gravity. This might be considered, as a matter of fact, as one of the most fundamental subjects (Agamben, 2006) that emerge when the circus device reaches out to an audience. In order to deepen the exploration of this subject, this article narrows down its study to an idea of contemporary circus that is based around the skill and performative potential of the human body.

Because of its ancient roots and its opening to new possibilities, circus arts compose a universe whose aesthetics are directly linked to risk and centred around the physicality of each artist. Acrobats and circus people are everyday performers of sequences of stable and dynamic states, bound with moments of rupture, imbalance and danger (Goudard, 2013). This means that, whether the performer uses objects or an apparatus in the mise en scène or not, each act includes a series of motion, pauses, and transitions of acrobatic gesture that evolve through different ways of managing weight - the performer's own body, that of the partner, the manipulated object - showcasing an inexorable pull towards the ground, in other words, the force of gravity. 
Besides, the execution and the perception of acrobatic gestures embody a tension between pleasure and fear (Wallon, 2013) that is still rooted in an Aristotelian idea of catharsis shared by other forms of spectacle or ritual that involve death risk for the performer. Therefore, ancient gladiator games, modern day toreo (bullfighting), high level gymnastics or specific works of performance art, for example, are often compared to the performative dynamics of risk in circus acts. By exposing themselves to physical danger, circus performers invoke the audience's fear as well as their joyful relief when the pirouette works, and the risk fades away. This dynamic conveys a symbolic fear of death with a real, human terror to what is inevitable and uncontrollable. From this perspective, in our collective imagination, acrobatic gestures act as a vehicle of achieving the impossible and managing not to collapse under the pressure of the forces that condition our physicality. Emmanuel Wallon (2013) alludes to this concept when he refers to Circus as the place where the instability of bodies and objects become evident, revealing their precarious nature from a perspective that transcends the physical level. This aesthetics of risk, which is characteristic of the circus device, face the audience with its own physical vulnerability and material comfort. Thus, one of the essential functions of Circus as a device is to confront both performers and viewers with their common physical and mortal truth.

\section{Why gravity matters}

Gravity, in both its physical and semantic assumptions, conditions human identity at an essential level. From an ecological perspective conceiving the body as inseparable from its environment, the awareness of one's own body implies an immediate and complementary consciousness of both one's incommensurability and the world's immensity (D'Andrea, 2017). The awareness of our own mortality is a fundamental reflection that continues to define our self-perception, even if it is commonly forgotten or unconsciously rejected.

In a pre-motion and pre-cognitive state of the body (Andrieu, 2013; Andrieu and Burel, 2014), the notions of subject or person do not exist to the interactions between the body and its environment, which are immersed in a mutual, qualitative belonging (D'Andrea and Sirost, 2017). Nevertheless, it is in the pre-motion state where the deeper layer of the muscles self-regulate in order to resist the force of gravity, and it is in the same deep layer of the muscles where the emotional and affective state changes are registered in the individual. This means that, at a pre-conscious level, the way in which each individual manages their own weight reveals expressive and psychological elements, a single and personal way to face gravity (Godard, 1995). 
After pre-motion is when gestures and movement take place. According to Hubert Godard, the perception of a gesture is a global seize. Beyond the visual and the kinaesthetic nature of the perception of gestures, "each individual and social group (...) create and suffer mythologies of the body in motion, while cultural evolution controls or bans emerging attitudes of self-expression and perception of the other"1 (Godard, 1995, p. 224). For this reason, according to Godard, the way in which gestures are produced and perceived varies between different eras. The hypothesis that gestures persist throughout time, as we can find the same gestures emerging repeatedly in the history of images, is not new to semioticians. These persisting gestures would correspond to what art historian Aby Warburg called pathosformeln (1932/1999) ${ }^{2}$. Following Warburg's thread, Georges Didi-Huberman came to assemble in 2016 a travelling exhibition dedicated entirely to the visual analysis of uprising. Through essays, images and audio-visual material (works of art and documents), Didi-Huberman states that there is a coherent correlation between gravity-defiant gestures and the resistance to gravity intended as the socio-political facts of our history, which he calls la lourdeur des temps (the heaviness of times). From this semantic match, Didi-Huberman defends that uprising, gravity defiance, is a sort of endless gesture that relates with the Freudian concept of freiheitsdrang, a drive for freedom (Didi-Huberman, 2016). Uprising then would be present in the most subtle and automatic of the human actions, such as inhaling, up to the most extreme of the voluntary physical actions, where acrobatic gestures are found. Our biorhythm, as well as the evolution of our species from quadrupeds to bipeds, would tell the story of our rejection of gravity (Mondzain, 2016), while in the present era characterised by the feeling of groundlessness, isolation, uncertainty and virtual communications, free fall seems to be a new visual and social paradigm. Gravity becomes thus a free fall towards the future as mankind accelerates its downfall into the uncertainty of 'tomorrow'.

When asked to write for about the new millennium, Italian writer Italo Calvino stated that the seeking of lightness can cover and reveal the hardships of the world at the same time (Calvino, 1988). An antidote to gravity, we fight our mortality and the heaviness of times with leggerezza (Italian for levity). Circus arts have historically shown this potential. Acrobatic movement and gestures act as a vehicle of levity, becoming an effortless image of vitality, achieving the impos-

\footnotetext{
1 Quote translated from French by the author.

2 According to Warburg, the pathosformeln could be mapped in an image atlas through an anachronistic approach (Warburg, 1921-1929), in order to explain the evolution of human beings' psychological affections as expressive potential. Being a part of a much broader study field, the concept is mentioned but not exhaustively explained in this article.
} 
sible and counterbalancing the world in order to reverse adversities and to visually overcome gravity (Peignist, 2009). It will come as no wonder to find, thus, the first traces of acrobatic gestures in ancient civilizations to be related to Dionysian practices, rituals and ancient shamanism, as "circus was originally born out of the need for metaphors of quotidian activities"3 (De Ritis, 2008, p. 54).

The perception of gravity-defiant gestures is associated then, at different levels, with a symbolic resistance to heaviness and hardship, as this association arrives to our days through the history of art. Circus acts, because of their gravitydefiant potential, traditionally cover this symbolic function at a social level and act as a collective cathartic mechanism that seeks levity, physical transcendence and wonder.

This dynamic is not only poetic, it happens also at an inner physiological level. In fact, the role of gravity in the sense of movement is fundamental for certain study fields of Neuroscience ${ }^{4}$.

Because the human vision works as a multimodal experience, while the acrobatic movement is perceived as something detached and independent of the viewer's body, the viewer simulates at a kinaesthetic level the physicality of the acrobatic movement as if it could have been his/her own. In very simple words this would be an explanation of the mirror neuron theory, there is a perceptive correlation between a body that executes an action and another that observes it.

According to neuroscientist Vittorio Gallese, "other mirror mechanisms are involved in our capacity to directly apprehend the emotions and sensations of others because of a shared representational bodily format" (Gallese, 2017, p. 188). So, when perceiving others, we subjectively experience the same emotion or sensation while not fully experiencing the qualitative content. This dynamic enables a notion of intersubjectivity that Gallese defines as "intercorporeality - the mutual resonance of intentionally meaningful sensorimotor behaviours" (Gallese, 2017, p. 188). To sum up, the perception of actions activates in the viewer an inherent, pre-conscious empathy that escapes the grasp of our will. This empathy is composed by both physiological mechanisms and associations of meaning, which are determined by the previous experience and the corporeality of both performer and viewer. This instant empathy nurtures the auto-poetic loop that Erika Fischer-Lichte (2014) identifies as the immediate meaning exchange between the performer and the viewers during performative actions.

3 Quote translated from Italian by the author.

4 The parallelism with which the subject has been treated so far in both scientific and performative fields might find a common origin in the $20^{\text {th }}$ century through the development and different applications of Biomechanics. 
Because all the previously mentioned mechanisms activate, emerge or result from a circus performance, a plural, multidisciplinary perspective seems like the only coherent way to a possible understanding of Circus as a device whose most essential subject would be the relationship between the human body and the physical forces by which it is bound. Such an approach, which unveils the correlations between corporeality and human identity, can be applied back to the study of performative practices in order to produce new knowledge value in both practical and theoretical levels. Thus, Circus' creative potential may be understood beyond disciplinary boundaries, and beyond the glass walls of our institutional divisions.

\section{Putting things into context: the new circus as a symptom of a major performative turn}

At this point, the approach of this paragraph will focus on the development of circus arts in contemporary times and in the western areas of the world, to briefly contextualise what is commonly known as nouveau cirque (it is not my intention to dive into the possible controversies of the term in the current article) and contemporary circus.

According to historian Pascal Jacob (2016), what we commonly call nouveau cirque originated in France in 1974 with Alexis Grüss' show "Cirque à l'ancienne" (French for "Circus in a traditional way"). The show reconstructed the spirit of the $18^{\text {th }}$ century equestrian circuses in order to celebrate the bicentenary of Philip Astley's arrival in France, as it was inspired in Astley's own shows. The show was the first to feature elements that characterise contemporary circus even today, such as: a reduced cast, live music, the polyvalence of the artists, visual sobriety in scenography and costumes, and an effortless style in the acrobatic gestures, as if circus were some kind of "natural extension of mankind's love of challenge to the level of art" (Albretch, 2006, p. 9-14). The sobriety of the show introduced audiences to the almost holy character of the circus ring, and to the possibility of conceiving Circus as an art form (Albretch, 2006), thus a creative device. Grüss' "Cirque à l'ancienne" is considered to be a sort of turning point, but its contribution to the future of Circus comes from reinventing a past that had been a moment of reinvention itself as well. This need for renewal was the result of many different processes. In very general terms, the social upheaval as well as political and cultural transformation (reaching a moment of climax in 1968) blended with the reality of a sector that did not find audiences as easily as in the previous decade. This situation led to a series of attempts of innovation to draw in a new audience which were mostly unsuccessful due to a lack of significant structural 
change (Jacob, 2016). Reinventing the past in order to look for future horizons is a mechanism found in Counterculture and Postmodern movements, that contextualise the spirit of time in which the revolution of nouveau cirque took place. However, and because it did not have the recognition of cultural politics until very late, Circus has been academically underrated and therefore not frequently included in the history of art.

If nouveau cirque in its many assumptions is a sort of avant-garde, it seems absurd not to relate it to other artistic forms and expressions that in the very same years were enlarging art's boundaries. Such perspective would allow the understanding of nouveau cirque as another ripple of what Erika Fischer-Lichte (2014) calls "the performative turn". This term refers to an inflection point in art history (mostly evident in the 60s and the 70s) leading to a new paradigm that will find performativity in its core and resulting in a general movement towards artistic multidisciplinarity (Fischer-Lichte, 2014). Embodiment, as well as actions' meaning and politicisation, became central matters in artists' work and methodology, hence the fundamental importance of the body-gravity relationship in artistic development.

In fact, the acceptance of body weight and gravity was one of the major revolutions of dance during the last century. The deconstruction of the idealised body promoted by classical dance in favour of a natural corporeality, as one of the fundamental principles of postmodern dance (Louppe, 1997), gave greater emphasis to the singular gestures and identity of the performer, the choreographer, and the viewer. The emergence of somatic approaches within western traditions also contributed to an increasing multidisciplinary interest in gravity awareness and management as a source of well-being. In the cases of artists like Paxton, Forti or Brown, for example, these different ways to move explored gravity in a direct way (be it contact improvisation or the dawn of vertical dance) as they were not far from acrobatics. Because of the elusive nature of performative actions, writing, notating, and instructing became relevant ways of preserving creation (Lista, 2017). Writing also implies authorship, hence the increasing development of the concept cirque d'auteur, whose application seems recent compared with the early use of the same concept in dance or theatre.

The holiness of the ring in "Cirque à l'ancienne", as well as its sober, essential character, relates to the state of the contemporary theatre at the time. The new idea of circus that was developed from then on was built around a specific 'meaning' or 'intention', introducing dramaturgy and narration as an agglutinant element to privilege cohesive creations, opposite to the traditional juxtaposition of 
acts that characterise traditional circus. According to Pascal Jacob, the origins of contemporary circus are found in the final show of the seventh class of graduates from CNAC, "Le cri du camaléon" (1995), marked by the principle of "dissolution of the act in favour of a global implementation of the show, where acrobatic gestures always serve an actual purpose"s (Jacob, 2016, pp. 218-238). Also drawing from the basis of conceptual art, the idea and the process behind the creative work are preponderant and conditions considerably the finished product, as we can see for example during the years in which Franco Dragone directed many Cirque du Soleil shows, especially Quidam which premiered in 1995 (Albretch, 2006).

Understood as a ripple of the performative turn, nouveau cirque is enhanced by the late avant-gardist development in the arts and their significant approaches onto the relationship between gravity and corporeality. The heritage of postmodern currents in contemporary dance and theatre techniques are still taught together with traditional acrobatic and juggling disciplines, as they have ever since the founding of the first two European circus schools, respectively by Fratellini and Grüss in 1974.

Nonetheless, the major turn came in 1978, when the French Ministry of Culture officially recognised circus as an art form and as a part of the country's cultural and historical heritage (Wallon, 2013). Circus would then become a sector with dedicated funds allowing further expansion and creative development, as it happened notoriously in the francophone areas of Europe and North America. Let us keep in mind through the INAEM case described at the beginning of this article, that the equivalent process only took place in Spain in 1990. The end of the 1970s would see the first edition of the main European circus festivals and the next decade would see the founding of superior circus schools like Centre National des Arts du Cirque (Châlons-en-Champagne) or École National de Cirque (Montréal), followed by a fast international proliferation of circus schools during the 1990s and early 2000 s.

Finally, getting to the last decades, contemporary circus companies have managed to become multinational enterprises. Taking Cirque du Soleil (founded in 1984) as an example, the company's development does compare to successful contemporary artists whose careers seem to become unquestionable, whose work, being produced through big enterprises, cannot escape artistic branding. It might be tempting to compare Cirque du Soleil's souvenir shop (that in prepandemic times could be found under each production's big top, at a Disney

\footnotetext{
5 Quote translated from French by the author.
} 
World resort, in several casinos in Las Vegas and at the airport of Montréal) with the gift shop at multinational art museums.

To sum up, through nouvean cirque as well as through the other late $20^{\text {th }}$ century avant-gardes (from the performative turn forward), the subject of gravity management has been established as one of the fundamental questions to inquire into human identity from a perspective that is both physical and poetic. A multidisciplinary chronology of the arts can show how Circus has been academically underrated, perhaps because it did not have the recognition of cultural politics until very late. Contemporary circus continues to stage humans and their correlation with the force of gravity, no matter how humble or how large-scale the productions might be. What seems to change is the institutional legitimation and the apparently consequent recognition in the viewers' imaginaries.

\section{Practical examples: a cartography of the subject through the work of contemporary artists}

The studies about gravity as a conditioning factor of human identity tend to appear in research areas related to phenomenology, movement analysis, ecology, dance or kinesiology, whereas the subject also emerges frequently in the fields of semiotics, psychology or literature. Meanwhile, the existing literature about circus arts tends to approach the subject in a disciplinary-oriented way that is either historical, focused on the cultural production side of each individual project, or tackling very wide and general aspects, sometimes unrelated to concrete examples. In other words, what circus 'is' and what it 'is not'. I believe that, through the lens of a complex perspective, it is possible to combine both approaches to better understand circus arts as the complex heterogeneous universe that they are. A line of thought capable of bonding together the fundamental aspects that operate through the circus device, applied to the study of contemporary creation, could be a solution to better understand both circus and its subjects.

The goal of this last section is to briefly explore and interpret the work of five artists that are currently active (and not to give a generalist explanation of their creative or intellectual capital), in order to provide concrete case studies of the concepts and mechanisms described in the previous pages.

As a researcher, I am interested in artists whose creative processes and results are hybrid and blend elements, methods, and procedures in experimental ways that do not necessarily respond to a disciplinary thought. Their works, which I have encountered during my studies or my personal experience, are focused on the problematic of gravity as a condition to human identity, from a performative 
perspective. Some creators have defined themselves as circus choreographers or performers and some of them have not, but all of them have to do with staging the human body and its relationship with the uprising-suspension-fall parable.

Aurélien Bory is a theatre director (Cie 111, based in Toulouse) and former trained physician, whose work has often been defined as 'metaphysical theatre'. His work, which some critics have also related with currents of Minimalism, constantly deals with the relationship between humans, verticality and gravity, unveiling the inexorability of the laws of physics with which we all live. The word 'acrobat' is etymologically bound to the intention of reaching the heights, as Bory reminds through his work "Azimut", where the members of the acrobatic troupe of Tanger recreate the old theatre illusion trick of the flying machine to hover above the stage. According to the artist, there is no better place than a theatre for visualising the vertical axis of gravity, because of its structure and mechanism. In the words of the artist "everything that stands upon the stage will stand outside, in the world" (personal interview to the artist, 2017). While in pieces like "Géométrie du cautchouc", "Espaece", or "Plan B" the performers are nameless, "Qu'estcequetudeviens?", "Plexus" and "aSh" are solos and portrait pieces, made with and for the performer. Plexus portrays a dancer whose life has been determined by migratory movements. In the show, the dancer Kaori Ito seems to be trapped in a cage made of theatre strings, becoming a puppet of gravity. When I interviewed Bory about this piece, he quoted "On the marionette theatre", an essay by Henrich Von Kleist written at the beginning of the $19^{\text {th }}$ century and also revisited by Hubert Godard in "Le geste et sa perception". According to Von Kleist (1810), dancers should learn about movement from puppets. Because puppets are subject to gravity, their involuntary movement organises their weight in the most graceful way. This romantic idea of grace as weightlessness has pierced through the history of dance, influencing dance evolution as well as beauty canons and gender imaginaries that persist until nowadays.

While postmodern and contemporary dance would develop against the principles of classical dance, the search for the state of grace is still present in the work of contemporary choreographers, often through the most advanced uses of technology. Choreographer Kitsou Dubois' work invites the performers' body to move in altered gravity conditions, from suspended bars to underwater training and choreographies designed to be executed during parabolic flights. By moving in microgravity, Dubois manages to enlarge the body's possibilities in ways that radically escapes from the physical conditions of daily life, enabling the performer's perception to nearly lose the limits of his or her own body into a state of grace that is not that far from Von Kleist's essay. 
The ecological relationship between the body and its habitat is at the core of choreographer and dancer Maria Donata D'Urso's work (Cie Disorienta, based in Paris). These habitats are often punctual scenographic objects and constructions inside and upon which the dancer's body will coexist by transformation, counterbalance and fragmentation, eventually disappearing as an individual within the whole system. The dancer's formation is originally related to the work of Alwin Nikolais, in which the dancer's work is but an equal part of the elements that compose each performance (Boisseau and Gattinoni, 2011). In "Mem_brain. Strata 1", D'Urso deals with the concept of tensegrity. Tensegrity (a concept coined by genius architect Buckminister Fuller) is an architectural principle that regards the combination of tension and integrity among the different parts of a structure. The scenography of "Mem_brain" is ruled by this principle and inspired by the work of sculptor Kenneth Snelsson, consisting in a series of metal bars held together by steel wires and the weight and pressure that the performer exercises upon them. In this context, the dancer inhabits the constant and delicate game of imbalances that are suspension and equilibrium. It is, somehow, an expression of a horizontal hierarchy in which each part of the structure - top and bottom, centre and periphery - share the same value and importance. Through this idea of suspension, which is a common trace in the artist's work, the habitat formed by imbalance and disequilibrium helps the performer to access a deep state of proprioception and body-awareness, redefining the romantic ideals applied to grace as weightlessness.

Suspension is also at the core of Chloé Moglia's work (Cie Rhizome). A trained trapeze artist, Moglia has developed throughout her career an approach to aerial acrobatics that is influenced by martial arts. Her work defines suspension as a practice of its own. This includes a minimalist approach to both the design of original aerial apparatus and traditional aerial acrobatics technique. The apparatus is often reduced to a single bar suspended in the air, a clean line that evolves in her different creations from big format trapezes to wide and curved drawings that cut through the air in both indoor theatres and outdoor spaces. In the case of Moglia's work, the notion of "sculpturestructure" as the main habitat for the aerialist evokes the importance of lines (shapes, contours, limits, boundaries) in our visual perception and imaginaries. Time seems to stretch in each suspension, as the acrobatic gesture eclipses the idea of acrobatic 'trick' in order to bring the presence and individual features of each performer to the first plane of attention. In the creations of her company Rhizome, evidencing and resisting gravity hits the audience as the most extraordinary thing. 
According to Fabio D’Andrea (2017), real physical awareness pushes our consciousness directly into a sort of qualitative belonging. Meaning, a realization of being an interrelated part of the environment. If the perception of acrobatic gestures in circus acts involves a kinaesthetic approach, then from a performative perspective, the viewer feels instinctively identified with the staging of acrobatic gestures and motion works. This is one of the most outstanding effects of the work of many circus creators whose approach to acrobatic gestures is willingly essential, reinforcing a performer-viewer identification. We all know what it is to carry our own weight and to face the physical forces that we see at play every second on stage. Because of this principle, essential acrobatic aesthetics seems to be the main key to an incredibly poetic visual and performative work.

Finally, Inbal Ben Haim is an Israeli artist and aerial acrobat specialised in aerial rope. Her promising work understands circus from its visual potential to create clear aesthetic bonds between the notions of identity, territory and belonging. Inbal sees in the aerial rope a line that literally links the body of the aerialist to the ground, a concept that she pushes forward in both versions of her work "Racine(s)". The outdoor version of "Racine(s)" takes place underneath a tree, while the indoor version of the show is designed for theatre spaces and counts on a larger, stunning scenographic device. In this work by the aerialist, earth is always present. In her shows, earth covers the stage or falls from the treetop, and the performer is in permanent contact with this element. Through the symbolic use of earth, the physical bond between the body and the ground serves to visualise the relationship between the person and the territory. The aerial ropes, her element as an acrobat, become giant roots that dominate the stage as suspension and detachment from the floor - symbolically ground, earth and territory at the same time - compose a powerful image of belonging and identity reformulation.

In conclusion, contemporary creation in circus, understood from a wide performative perspective, responds to the ongoing development of its late avantgarde, that is part of the history of art as a further consequence of its evolution around the last quarter of the $20^{\text {th }}$ century. The artists whose work I chose to describe as an example are comprehended in a vast and ever-changing panorama of contemporary creation. At the same time, their work demonstrates different approaches to the use of circus to maximise, study and question the relationship between human beings and gravity. This is possible using Circus as a creative device, whose understanding is possible thanks to a complex point of view that sees creativity from its transversal potential to address essential problems of the human identity. 
It seems undeniable that each era reformulates the correlations between corporeality and identity (Godard, 1995). The present in which this article was written is marked by a series of crises that deeply transform the identity constructions around the body. Nearly a year of an ongoing pandemic, isolation, fragility, social distance, mobility restrictions, "essential needs" and virtual connection, seem to have started a new self-interrogation cycle of our body mythologies (Godard, 1995). The further development of Circus in the future will depend on three aspects: how the imaginary of Circus will respond to the ever-challenging paradigms of our present, how this imaginary will find new interpretations in the eyes of the viewers and how institutions will choose to recognise, facilitate and protect it.

\section{Bibliography:}

Agamben, G. (2006). Che cos'è un dispositivo? Nottetempo.

Albretch, E. (2006). The Contemporary Circus. Art of the Spectacle. The Scarecrow INC.

Andrieu, B., Burel, N. (2014). La comunication directe du corps vivant. Une émersiologie en première personne, "Hermès", no. 68.

Andrieu, B. (2013). Le corps en première personne: une écologie pré-motrice, "Movement \& Sport Sciences - Science et motricité", no. 81.

Boisseau, R., Gattinoni, C. (2011). Danse et art contemporain. Nouvelles Éditions Scala. Bory, A. (2017). L'espèce dans l'espace. Actes-Sud Papiers.

Calvino, I. (1988). Lezioni Americane. (Ed. 2016) Oscar Moderni.

D’Andrea, F. (2017). Imago mundi. L'expérience du corps dans le monde, “Corps”, no. 15.

D’Andrea, F., Sirost, O. (2017). Des écologies et des corps, “Corps”, no. 15.

De Ritis, R. (2008). Storia del Circo, dagli acrobati egizi al Cirque du Soleil. Bulzoni Editori.

Didi-Huberman, G. (2016). Ce qui nous soulève, [in:] Soulèvements, Gallimard. Catalogue of the exhibition "Soulèvements", curated by G. Didi-Huberman.

Fischer-Lichte, E. (2014). Estética de lo performativo. Abada Editores.

Gallese, V. (2017). The Empathic Body in Experimental Aesthetics - Embodied Simulation and Art, [in:] V. Lux, S. Weigel (eds.), Empathy. Epistemic Problems and Cultural-Historical Perspectives of a Cross-Disciplinary Concept. Palgrave.

Godard, H. (1995). Le geste et sa perception, [in:] M. Michel, I. Ginot (edss), La danse au XXème siècle. Bordas.

Goudard, P. (2013). Esthétique du risque: du corps sacrifié au corps abbandoné, [in:] E.

Wallon (Ed.), Le cirque au risque de l'art. Actes-sud Papiers.

Jacob, P. (2016). Une histoire de cirque. Seuil/BnF. 
Lista, M. (2017). Dance is Hard to See. Introduction. A Different Way to Move, [in:] A Different Way to Move. Minimalismes, New York 1960-1980, catalogue of the exhibition curated by M. Lista. Berlin, Hatje Cants.

Louppe, L. (1997). Poétique de la danse contemporaine. Contredanse.

Mondzain, M.J. (2016). À ceux qui sont sur la mer, [in:] Soulèvements, Gallimard. Catalogue of the exhibition Soulevements, curated by G. Didi-Huberman.

Morin, E. (1990). Introduction à la pensée complexe. (Ed. 2005) Seuil.

Peignist, M. (2009). Histoire anthropologique des danses acrobatiques, "Le corps dansant", no. 7.

Pontremoli, A., Venura, G. (2019). La danza: Organizzare per creare. Scenari, specificità tecniche, pratiche, quadro normativo, pubblico. Franco Angeli.

Topin, N. (2001). L'analyse du mouvement, une danse du regard: l'enseignement d'Hubert Godard. "Nouvelles de danse", 46-47; "Incorporer", 100-113.

Von Kleist (1810). Sul teatro di marionette. (Ed. 1996) La Vita Felice.

Wallon, E. (2013). Introduction. La gravité plus la grâce [in :] E. Wallon (Ed.), Le cirque au risque de l'art. Actes-Sud Papiers.

\begin{abstract}
This article aims at understanding Circus as a creative device in order to provide an alternative approach to the study of contemporary circus creation. To this effect and from a plural, multidisciplinary perspective, the article will be organised in four main parts. Justifying Circus as a device for staging the relationship between the human beings and the force of gravity; specifying why this relationship is indeed at the very core of human beings' experience and identity matters; contextualising nouveau cirque within the evolution of artistic avant-gardes from post-modern currents to our days; and providing a series of practical examples of these first two points by studying selected works from a series of contemporary artists. Such approach evidences Circus' aesthetics of risk as a convergence point for researches in corporeality and performativity, while allowing a parallel study on the problematic of gravity as an essential condition for human identity. From both its physical and poetic aspects, this subject evolves radically through the late 20 th century to the paradigms of our present, as it is visible in the work of active artists such as Aurélien Bory, Kitsou Dubois, Maria Donata D’Urso, Chloé Moglia, Yoann Bourgeois or Inbal Ben Haim.
\end{abstract}

\title{
Keywords: circus, device, gravity, corporeality, identity, multidisciplinarity, nouveau cirque, contemporary creation
}

